\title{
Hope as a Lifeline: Imatinib Discontinuation in Patients With Oligometastatic Gastrointestinal Stromal Tumours
}

\author{
LENA FAUSKE ${ }^{1,2}$, PERNILLE H. WÆRSTAD ${ }^{3}$, IVAR HOMPLAND ${ }^{1}$ and $\emptyset$ YVIND S. BRULAND $^{1,4}$ \\ ${ }^{1}$ Department of Oncology, Norwegian Radium Hospital, Oslo University Hospital, Oslo, Norway; \\ ${ }^{2}$ Department of Interdisciplinary Health Sciences, Institute of Health and Society, University of Oslo, Oslo, Norway; \\ ${ }^{3}$ Institute of Clinical Medicine, Study of Medicine, University of Oslo, Oslo, Norway; \\ ${ }^{4}$ Institute of Clinical Medicine, University of Oslo, Oslo, Norway
}

\begin{abstract}
Background/Aim: This study explored how highly selected oligometastatic gastrointestinal stromal tumour (GIST) patients subjectively experienced the discontinuation of imatinib (IM) treatment. Patients and Methods: Being an exploratory qualitative study, we applied a phenomenological and hermeneutical approach. We conducted in-depth semistructured interviews with nine oligometastatic GIST patients who were in long-term clinical remission. The gathered data were interpreted using a thematic analysis. Results: The analysis of the interview data revealed four main themes; getting one's life back, fear of recurrence, hope as a lifeline and the pros/cons of participating in this clinical trial. The participants disclosed that hope of being cancer free and without the side-effects of IM was essential for both participating in this study and enduring the uncertainty of drug discontinuation. Conclusion: Use of a qualitative approach in clinical trials can result in a better understanding of patients' perspectives and therefore lead to improved clinical practice.
\end{abstract}

Gastrointestinal stromal tumour (GIST) is recognised as the most common sarcoma of the gastrointestinal tract (1). The majority of GIST patients can be cured by means of surgery, although $15-20 \%$ already exhibit overt metastases at the time of primary diagnosis, while approximately $40 \%$ of GIST patients initially thought to have only local disease will

This article is freely accessible online.

Correspondence to: Lena Fauske, Department of Oncology, Norwegian Radium Hospital, Oslo University Hospital, P.O. Box 5960, Nydalen-0424, Oslo, Norway. Tel: +47 2278123, e-mail: lena.fauske@ous-hf.no

Key Words: Gastrointestinal stromal tumours, tyrosine kinase inhibitors, imatinib, discontinuation, qualitative research, sideeffects, psycho-social, hope. eventually experience metastasis (2). Treatment with imatinib (IM) and other tyrosine kinase inhibitors (TKIs) has dramatically increased lifespan in metastatic GIST patients, with the median survival being approximately seven years (3). Thus, metastatic GIST may be regarded as a chronic disease. Despite this, most patients will eventually experience drug resistance in relation to IM (4) and second(5) and third-line TKI therapy (6).

Patients with metastatic GIST require daily administration of IM to keep the disease at bay (6). Practically all patients who receive IM experience side-effects, with the most common being anaemia, periorbital oedema and watery eyes, diarrhoea, muscle cramps (typically in the hands and legs), fatigue and nausea $(7,8)$. As severe adverse effects are relatively rare, IM is considered a moderately to welltolerated drug by the medical community (6). However, it is important to recognise that the patient's perspective, concerning the side-effects of IM, may differ from the medical perspective. For instance, a recent qualitative study found that more than half of the 20 participants described partially debilitating side-effects that had a detrimental impact on their lives (9). This study, together with another qualitative report involving GIST patients who were receiving TKI treatment, revealed that the participants experienced side-effects that impacted their daily lives in both negative and challenging ways, which forced them to adapt to 'a new normal' $(9,10)$. In addition, GIST patients receiving TKI treatment have been shown to experience significantly higher (30\%) levels of fatigue when compared to healthy controls $(15 \%)$, and an association was reported with both a lower quality of life (QoL) and an increased level of impairment in all studied domains (11).

It is recommended that patients with metastatic GIST receive IM for the rest of their lives or until disease progression occurs (6). IM was initially developed as a very effective treatment for chronic myeloid leukaemia (CML), and several studies have found that discontinuing IM in CML patients following long-term complete clinical and molecular 
remission is safe (12). Moreover, some patients remain in deep molecular remission without IM, while for those who relapse, the reintroduction of IM leads to new remission (12). For GIST patients, however, there is substantial evidence that IM and other TKIs fail to completely eradicate metastatic GIST and, further, that disease progression is inevitable if IM treatment is discontinued (13-15). While continuous (or lifelong) IM administration remains the standard treatment approach for patients with advanced GIST, an experimental treatment strategy for highly selected patients has been proposed (15). This strategy involves discontinuation of IM in patients who have received long-term IM administration and undergone resection of oligometastatic disease. It is now being explored in the phase-two Scandinavian Sarcoma Group (SSG) XXV 'Stop-GIST Trial' (ClinicalTrials.gov Identifier: NCT02924714), wherein patients with oligometastatic GIST who have had the metastases surgically resected (R0/R1) or radiofrequency ablated, and who have been treated with IM for more than five years without any signs of progression, discontinue the IM treatment.

Stopping a medication believed to keep GIST in remission could prove to be mentally challenging for trial participants. Hence, the primary aim of the current study was to explore how nine GIST patients who were enrolled in the SSG XXV 'Stop-GIST Trial' conveyed their experiences of participating in the study, focusing on their ambivalence concerning taking part in the study. The secondary aim was to explore if stopping IM changed the GIST patients' QoL with regard to subjective side-effects experienced when compared to what they had experienced when taking IM prior to participating in the study. In addition, we sought to determine how the present qualitative study could serve to expand our understanding of the patient perspective regarding participating in such a clinical trial.

\section{Patients and Methods}

Patients being treated at the Norwegian Radium Hospital (NRH), Oslo University Hospital (OUH) who were enrolled in the SSG XXV 'StopGIST Study' were included in this research. Here, the discontinuation of IM was deemed justified in highly selected patients who had a confirmed diagnosis of metastatic GIST and had received TKI therapy involving IM for longer than five years for oligometastatic GISTs ( $\leq 3$ metastases) that were initially documented to be responding to treatment. Their cancer had to be stable when on IM treatment, while no focal progression in known metastatic sites was accepted. At the time of enrolment in the study, the metastases were either no longer visible on their computed tomography/magnetic resonance imaging (CT/MRI) images or else had been removed via complete surgical resection (R0/R1 resection) or radiofrequency ablation (RFA).

We applied an exploratory qualitative research design involving a phenomenological and hermeneutical approach to analysis. In qualitative research, phenomenology is a concept that indicates an interest in understanding phenomena from participants' own perspectives and describing the world as it is experienced by them
Table I. Demographic and clinical information concerning the nine participants.

\begin{tabular}{lc}
\hline Age $^{1}$ (years) & \\
Median (range) & $66(50-85)$ \\
Gender & 4 \\
$\quad$ Female & 5 \\
Male & \\
Relationship status & 6 \\
$\quad$ Married & 1 \\
Cohabitating & 2 \\
Single & $7(6-21)$ \\
Time since primary diagnosis (years) & \\
$\quad$ Median (range) & $6(5-16)$ \\
Time receiving systemic treatment (years) & \\
$\quad$ Median (range) & 3 \\
Primary tumour site & 3 \\
$\quad$ Stomach & 2 \\
Small bowel & 1 \\
Duodenum & \\
Rectum & 5 \\
Metastatic site & 4 \\
Liver & \\
Peritoneal & \\
Metastatic status & 5 \\
Synchronous & \\
Metachronous & \\
Recurrent disease following drug discontinuation & \\
Status at second interview & 5 \\
\hline
\end{tabular}

${ }^{1}$ At the time of drug discontinuation.

(16). In the current study, we sought to explore the experiences of individual GIST patients in their specific life contexts. This form of research has a strong focus on reflective interpretation, as expressly stated by Heidegger, who asserted that description is inextricably linked to interpretation (17). Comprehension is based on both the participant's and the researcher's preunderstandings, as well as on the context, and it develops throughout the entire research process (18).

Patient population. Four women and five men from the NRH OUH who were enrolled in the SSG XXV 'Stop-GIST Trial' were approached regarding possible participation in the qualitative study, and they all agreed to take part. The participants had a mean age of 66 years (range $=50-85$ years) $($ Table I). In the results section of this paper, the participants are identified as P1-P9.

Procedure. All of the participants were recruited by their treating oncologists at the NRH OUH. Each participant received a letter providing detailed information about all relevant aspects of the study. They were informed that participation would not affect their treatment and that they were free to withdraw from the study at any point without penalty. The data protection officer at the NRH OUH approved the study (approval number 2016/15358), and written informed consent to participate was obtained from all of the patients.

The first author conducted the first round of interviews shortly after the participants had discontinued IM. The interviews lasted from 19-65 minutes. The first and second authors conducted the second round of interviews during subsequent scheduled clinical follow-up appointments according to the SSG XXV 'Stop-GIST 
Table II. Questions for the first interviews.

\begin{tabular}{ll}
\hline Tell your story & From when you first became ill and received your diagnosis, \\
& how has life been and how is it up to today \\
\hline Perception of your life situation. & - The effect of the condition and its treatment on your daily life: \\
What can you tell us about living & Partner \\
with a chronic cancer? & Family \\
& Friends \\
& Work \\
& Leisure time \\
& - Physical and practical consequences of the cancer and its treatment \\
& - Thoughts concerning the emotional and existential consequences of the cancer and its treatment \\
& - How living with a chronic has affected you as a person \\
What was your experience with the & - Information \\
healthcare services and the follow-up? & - Communication (via polyclinic) \\
& - Support and safety net \\
How did you feel about discontinuing IM? & - NAV (Norwegian Labour and Welfare Administration) \\
& - Invitation and information \\
How is your life today (without IM)? & - Expectations \\
& - Sxistential reflections \\
What are your current thoughts & - Daily life: relations, social life, leisure time, work \\
about the future? & - Existential reflections \\
Is there anything you would like to & - Fear of recurrence \\
mention that I haven't asked about? & \\
\hline
\end{tabular}

Trial' protocol at the NRH OUH $(n=2)$ or by telephone $(n=7)$ when necessary due to restrictions related to the COVID-19 pandemic. The semi-structured interviews were transcribed verbatim by a medical secretary $(n=13)$ and the second author $(n=5)$.

The participants were invited to narrate their whole story from the time of diagnosis to the present day. Their experiences concerning their life as a cancer patient with metastases controlled by effective medical treatment were explored through the questions listed in Table II. The second interviews were conducted up to 24 months after the discontinuation of IM (Table III). All of the gathered data were stored confidentially, and all of the interview transcripts were deidentified.

Data analysis. We used a reflexive thematic analysis $(19,20)$ to identify patterns of meaning across the dataset in order to answer the research questions. The patterns were identified through a rigorous process of data familiarisation, data coding, theme development and revision. In the present study, the entire dataset was thoroughly coded in detail (inclusive and extensive) by hand by the first and second authors. Then, the codes were divided into categories, themes and concepts (19). Throughout the entire process of analysis, the researchers regularly returned to the original data to check the themes and quotes and ensure that the meaning had not been lost during either interpretation or translation (18).

\section{Results}

Prior to discontinuing IM, six of the nine participants described how the side-effects of the treatment had a detrimental effect on their lives. Once the side-effects had subsided or disappeared following discontinuation of IM, they reported having a surplus of energy, enjoying improved mental health and experiencing less challenges in daily life. The participants reported varying degrees of uncertainty regarding the possibility of recurrence after discontinuing IM and the implications that recurrence would have for their lives. Unfortunately, albeit not unexpectedly, five of the nine participants experienced GIST relapses (Table I). They were disappointed, although they managed the relapses well because they knew they could hope for a second remission upon restarting IM.

Getting one's life back. The most common side-effects of IM reported by our participants prior to discontinuation were muscle cramps, tiredness and fatigue, nausea and oedema, especially periorbital oedema. A lack of energy, in one form or another, was reported by the majority of participants. Some expressed how tiredness, including the resultant impaired memory, and physical challenges were among the complaints that had the most significant detrimental impacts on their lives, with some having to adjust their daily activities to make it through the day. P3 was one of the participants who reported having to deal with fatigue: 'I didn't have any surplus of energy; I would rather just relax and sit still. Before [the cancer/IM treatment], I used to work 
Table III. Questions for the second interviews.

Participants still without IM, no recurrence

How is your daily life today when compared with the situation when you were being treated with IM?

Family

Physical activity

Social life

Work

Leisure time

Muscle cramps

Nausea

Diarrhoea

Pains

Fatigue

Other

Fear of recurrence

Thoughts for the future

What has your experience of participating in the study been like so far?

Is there anything you would like to mention that I haven't asked about?

Patients who have re-started IM treatment following recurrence

What was it like to have a recurrence?

Receiving the (bad?) news

Information and follow-up

Existential reflections

Restarting IM treatment

What is your life like today?

Adverse effects of IM

Side-effects, family, socially, work, physically, existentially

What are your thoughts about having discontinued IM treatment?

Knowing what you know today,

would you do it again?

out a lot you know [...]'. However, three participants only experienced mild to moderate side-effects when on IM and, therefore, did not view life when on medication as being too much worse than before. This is exemplified by a quotation from P5: 'Of course, it was troublesome with the cramps and red eyes [...] but it was not constant, so I haven't had much trouble with IM, I must say'. These three participants pointed out that they were able to continue to work and to maintain a social life when on IM despite the side-effects.

The phenomenon of 'getting one's life back' after discontinuing IM is something that all of the participants experienced to some degree or another. As the adverse effects of IM disappeared in most cases, the participants experienced several positive changes in their daily lives, as well as in their physical and mental health, following discontinuation. Furthermore, the disappearance of sideeffects such as nausea, oedema, cramps and fatigue after discontinuation of IM improved their lives in a rather straightforward way, mostly through reducing the pain and discomfort experienced on a day-to-day basis. P1 described it in the following way: 'It was so wonderful in January when I stopped taking the medicine, to experience that every day you could feel the energy coming back more and more, every day you could look in the mirror and see that you were starting to look more like yourself. [...] I felt so healthy and somehow got my old life back'. After stopping IM, the participants experienced a feeling of renewed energy that they could dedicate to different activities that they had been unable to engage in for a long time, for example, working out, gardening and spending time with family and friends, which also served to improve their social lives. P7 stated that he was very tired, indolent and unable to exercise when using IM, which changed radically when he discontinued the medicine: 'I have noticed a lot of positive things, such as a desire to exercise. Waking up, I can't wait to jump on the treadmill, which has never happened before. So, life looks much brighter for me'. Some participants experienced very individual struggles with their specific symptoms. In particular, P2 struggled with massive oedemas and had to wake up several hours early in the morning to get ready for work: 'It was like having to pee out two one-litre cartons of milk every single morning'. She explained that the cramps and oedemas were resolved once she stopped taking the medication. In fact, as the side-effects loosened their grip on 
the participants' lives, many reported an overall increase in their mental health, affirming that they had a brighter outlook on life or felt more like themselves. P6 emphasised experiencing increased mental clarity as the feeling of fatigue lifted: 'I'm less unfocused and I have an easier time keeping up during conversations'.

When interviewed for the second time, the four participants who were able to continue without IM still reported enjoying lives that were vastly improved when compared to their situation while on IM. Due to experiencing less fatigue, they were now more physically active and had more energy to be social. They considered that stopping IM was an entirely positive experience. As P3 expressed: 'There are only benefits to quitting IM. [...] And we are followed up so very well. It was every third month, or fourth month, and now it is every six months'.

Fear of recurrence. If a patient consents to the discontinuation of treatment, there is always a risk of recurrence, which would necessitate the reintroduction of IM. The worst-case scenario is that drug resistance may eventually occur, which would require the patient to take an alternative medication that might be associated with more severe side-effects or, eventually, succumb to disease.

During the process of discontinuing IM treatment, the participants experienced varying degrees of uncertainty regarding the possibility of recurrence and the implications that it would have for their lives. Some voiced a fear of recurrence due to stopping medication, although most denied having much fear of this outcome. P8 thought about the possibility of recurrence almost every day: 'I think it can come back. If it does so, you just have to manage. It's not okay, but there is no other option. [...] But I feel I can handle it'. By contrast, P3 did not worry about the future at all. He was not afraid of either drug resistance or death: 'I never thought that I would die from this. [...] I cannot understand that there is any risk at all. [...] I really believe that I will not have a relapse. There are many other things to fear and worry about'. The majority of participants seemed to have made peace with the fact that they might have to restart IM treatment if they were diagnosed with recurrence, and two participants stated that they would have few qualms doing so. P5 expressed: 'The way I understand it, I have the opportunity to restart [IM] treatment if the cancer comes back, and seeing as how I had so few symptoms, I don't really fear restarting, even though I don't want to, of course". Nevertheless, uncertainty about the future affected the lives of many of the participants. Indeed, planning too far in advance proved difficult for many of them. P8 stated that he had not done so since he first became ill several years ago: 'No, I have not, I have not done that in a long time'.

At the time of the second interviews, five of the nine participants had experienced recurrence after discontinuing
IM treatment. Among them, some reminisced fondly about their time without IM and its side-effects. These were the participants who experienced debilitating adverse effects when on IM. P1 described the time without side-effects in the following way: 'I could really experience the feeling of being alive. Similarly, P8 described it as follows: 'living with the brakes removed'. In accordance with the findings of the first interviews, however, three participants did not notice a great contrast between life with and without IM treatment. The five participants who experienced recurrence prior to the second interviews emphasised that life without IM was better or much better than life when on IM. This was especially true for those participants who experienced damaging sideeffects when taking IM. For them, despite being aware of the danger of relapse, it was important to enjoy their freedom from side-effects for as long as they could.

The participants reacted differently to being informed that they had relapsed. Two stated that it was not a big surprise, although they were disappointed. They exchanged the hope of being free from cancer for the hope that they could restart IM and most likely experience a positive treatment effect. As P5 pointed out: 'I'm glad I participated [...] because I would probably have blamed myself if I had not tried'. Unfortunately, P7 was very disappointed and angry when his cancer recurred. He stated that he was not prepared for the possibility that the GIST could metastasise to his liver during the drug-free period, which had not happened to him prior to the IM discontinuation: 'No one mentioned that it could spread to other organs'. He seemed to blame the hospital for painting an overly positive picture of the SSX XXV study and regretted his participation because it had led to the worsening of the disease. P1, who experienced devastating side-effects before stopping IM, became very sad and reported a crippling feeling of fear when she received news of her relapse: 'It was a bit difficult to receive that message because I was so happy. I was healthy from GIST, it seemed fantastic, but I wasn't really. It's in my body and will probably be there my whole life, I think'. In addition, she also had to restart TKI treatment involving sunitinib, which made her very sick: 'I got $50 \mathrm{mg}$. It was pretty severe because it leads to even more side-effects than Glivec did'. After a while, her doctors had to reduce the dose, which lessened the severity of the side-effects and meant she was again able to resume a more active life.

Although most participants explained during the first round of interviews that they did not focus on negative feelings or fear, every one of them mentioned being anxious in relation to the regular CT check-ups they had to undergo. The fear of relapse and death, which more than half of the participants did not think about on a daily basis, appeared to be associated with such follow-up. P2 expressed her feelings about it: 'So I think a bit about whether there have been changes or not, but otherwise I do not let it control my life. 
But exactly two weeks between the CT scan and doctor's appointment, yes!'. Some participants emphasised that they had experienced the same fears when attending their scheduled GIST follow-up appointments before participating in the study and discontinuing IM.

Hope as a lifeline. Throughout the experience of becoming a metastatic cancer patient and learning to come to terms with their situation, and then while participating in a study that involved the discontinuation of the medication that had actively kept them alive, the participants never let themselves be completely overtaken by feelings of fear or uncertainty. The importance of having hope along the way was underlined by P1: 'You see, what you need is hope. At the very least, you need hope, and you need to get some of that spark back to live on and bring with you'. At the start of their journey as a patient with metastatic GIST, the participants had hope that IM would prolong their life significantly. Then, following their enrolment in the study, there came two additional types of hopes. The first such hope was that they might actually be free of cancer, able to declare themselves cured and, therefore, no longer be a 'cancer patient'. The second hope was that they could once again live a life without debilitating side-effects. P6, who had been plagued by fatigue when on IM, had this to say when talking about experiencing less side-effects after discontinuation: '[A]nd then maybe I'll have more energy. I'll have to hope for that'

These hopes lived on in the four participants who had not experienced a recurrence of their cancer. Interestingly, for the participants who had the possibility of a cancer- and medicinefree life stripped away the moment they received the results of their CT scan, hope was not yet lost. In fact, despite losing the hope of being cured, they knew that they could restart IM or another TKI and hope that the medicine would keep them alive for as long as possible. During the first interview, P4 expressed this sense of hope as follows: 'I hope it goes well. But if it doesn't go well, then okay, in that case we'll just have to go back to IM'. With hope as a lifeline, the participants chose to participate in the study and endure the uncertainty associated with the discontinuation of IM.

Participating in the study. During the first round of interviews, when asked about their experience of joining the study, the majority of participants affirmed that their overall experience had been very good. Both the initial information and follow-up were said to be satisfactory or even excellent. As P5 stated: 'I think it has been absolutely superb and the follow-up has made me feel so good. I can't praise them enough. [...]. I've been here quite often, every three months, and if there has been something I needed, I have called and received a reply'. All of the participants felt that they had good working relationships with the doctors, nurses and other staff involved in the study, although P7 commented that in the beginning he had felt a certain pressure to participate: 'When I heard about the trial, I was very hesitant because I thought "Am I going to be used as a lab rat just so someone can invent something?", but then I thought that maybe I should participate. [...]. Then, when I received good explanations of the trial from different doctors, I decided to do it'. Several participants needed time to decide whether to discontinue IM, although in the end, they chose to join the study. Save for P7, none of them regretted their participation.

The participants expressed various reasons for agreeing to participate in the trial. For many, it was due to the hope of being truly free of their cancer, being able to proclaim themselves cured and being able to move on to a new chapter in their lives. Part of being cancer-free would involve returning to a life without the unwelcome side-effects of IM. Many participants noted their desire to contribute to important research and help other patients with similar maladies through participating in a scientific study. As P2 expressed: 'I felt that it was important for me but also for others to be able to avoid all those side-effects, not to have to live as I have done for seven years'. Finally, a few participants mentioned that they considered the closer monitoring involved in the trial to be a welcome perk of participation. As P9 underlined: 'Then I get a closer follow-up'.

\section{Discussion}

This study represents the first in-depth qualitative investigation of how patients with oligometastatic GIST who are in stable and long-term remission while on IM experience the discontinuation of their daily medicine, assuming that they might be cured. This approach is a novel one in the field of metastatic GIST. Our findings indicate that the hope of being free from cancer and without the sideeffects of its treatment was essential in terms of both participating in this study and enduring the uncertainty associated with IM discontinuation. The certainty that they could restart IM or another TKI in order to prolong their life later provided new hope to those participants who experienced the disappointment of recurrence.

The importance of hope in relation to cancer patients has been discussed in a few prior studies. The majority of patients with severe cancer reported feeling that they had no other choice but to hope and, further, that life without hope would be unbearable and lacking in quality (21). In this context, hope could be seen as an important coping mechanism when needing to handle psychological stress $(22,23)$. However, hope is not always a constant and available resource. Indeed, it can ebb and flow and, sometimes, be altogether absent. 'The relationship between hope and coping is dynamic and reciprocal; each in turn supports and is supported by the other' (23). According to Macdonald et al. (10), GIST patients undergo an emotional journey in which crisis, hope, 
adaptation, coping and uncertainty affect their lives after they are diagnosed. This was also a well-known journey for our participants, who prior to the study were in a stable phase in which they managed everyday life on IM despite its sideeffects and, generally, had the hope of a long life expectancy despite some living with the fear of resistance. The discontinuation of IM, the medication that had kept them alive for years, was considered to mark them stepping out of a safe period and into a period characterised by a greater degree of uncertainty but also a greater degree of hope for a cure. Hope provides energy, although it also takes energy to maintain (21). Yet, the different qualities of hope might require different levels of energy to manage. Thus, the need to move from a state of coping to a state of uncertainty may have been balanced out for our participants by the more potent hope of being cured. It has also been noted that 'hope incites people to action and prevents them from passivity' (21) and, further, that it leads to the grasping of opportunities for additional treatment. We postulate that this new hope of 'being cured' prompted the participants to join the present study in an effort to seek out a means of improving their lives.

In our study, the main reason for the participants discontinuing the TKI treatment was the hope of living a cancer- and side-effect-free daily life. This finding is in line with the findings of prior research on CML patients (24), which showed that half of the participants (i.e., those not much concerned about relapse or those who experienced considerable side-effects) agreed to try TKI discontinuation. By contrast, those participants who were concerned about relapse or who had experienced few or manageable sideeffects did not want to try TKI discontinuation (24). Another study on patient adherence to TKI treatment (25) reported that cancer patients had to strike a balance between focusing on survival and focusing on QoL and, further, that patients who experienced more side-effects were more likely to preemptively discontinue their treatment. These findings contrast slightly with the findings of our study, as some of our participants agreed to enrol in the study despite experiencing very few adverse effects and little fear of recurrence. We interpret this to mean that the hope of being cured was more potent than the hope of simply remaining alive for as long as possible, which prompted them to participate. Our findings also indicate that the hope of being cancer-free and experiencing less side-effects was stronger than the fear of relapse or the desire to maintain the status quo.

It is vital not to underestimate the importance of shared decision making when asking patients to discontinue potentially vital medications such as TKIs. Evidence suggests that the use of shared decision-making tools leads to patients having more realistic expectations and greater satisfaction when receiving healthcare (26), and we believe that the same could be true for participants in clinical trials. In the present study, we found that the majority of participants were very pleased with the information and follow-up they received. However, one man (P7) reported that he had not been properly informed about the possibility of metastases in new organs of the body and, therefore, regretted his decision to take part in the study. We cannot be certain whether P7 was or was not informed about the possibility of this outcome, or if the information he received was provided in an insufficient or complicated manner, thereby leading to a misunderstanding. Previous studies concerning patient information and communication during clinical trials have shown that, while most patients consider the information provided to them to be easy to understand $(27,28)$, many patients have poor recall or a poor understanding of oral information (29, 30). This highlights the importance of thoroughly explaining the possible risks and consequences of participating in any clinical trial, especially one involving the possibility of disease progression. Yet, the other participants did not regret participating. In fact, several expressed that they would have regretted not taking part and would do so again, even knowing that they would experience recurrence. Those participants who experienced recurrence after the discontinuation of IM received confirmation that the daily intake of TKIs was necessary for them to stay alive and, further, that the experienced side-effects were a necessary price to pay for the rest of their lives.

Folkman (23) determined that hope can assist patients throughout the process of diagnosis, treatment and followup of an illness. Moreover, it is especially important in terms of managing uncertainty over time for patients with, for example, a chronic cancer (23). In the context of our study, we reflect on the importance of hope in relation to the process of recruiting patients. In particular, with regard to patients who experienced few side-effects and so had less reason to participate, we consider one of the factors that influenced their participation to be the way in which the involved healthcare professionals conveyed hope and the possibility of a potential cure. Several studies have found that hope can be enhanced via therapeutic interventions, which can prove effective in helping patients with cancer or another difficult prognosis. However, this is still not widely known among physicians (31). In addition, Verbrugghe et al. (25) stated that when healthcare professionals focus solely on the cold medical reality and so undermine hope, they end up losing the trust of their patients.

Aside from conveying the patients' experiences of participating in this study and stopping their daily IM treatment, one advantage of this qualitative study was to expand clinicians' understanding of the patient perspective voicing individual benefits and harms when it comes to participating in clinical trials. While quantitative research is intended to measure and count, qualitative research is designed to produce a large amount of textual data, with the researcher attempting to make sense of the material through 
sorting and interpretation. Thus, a qualitative researcher utilises analytical categories to describe and explain phenomena (32). If applied in a well-designed research project, qualitative methods can bolster clinical trials by increasing user involvement and revealing new areas of research that would otherwise remain obscured within the bounds of strictly quantitative studies (33). In our study, qualitative research made it possible to describe, explain and interpret the participants' individual experiences, as expressed in their own words, regarding side-effects, anxiety, hope, trust and feedback mechanisms. In this context, qualitative research focuses on meaning and understanding, rather than on what can be reduced to quantitative measures (33).

The understanding of hope as a recurring theme regarding why the patients participated in the study, endured the uncertainty and tackled the disappointment of relapse offers clinicians insight into participants' motives and experiences concerning involvement in clinical trials. In this case, the feedback regarding how the participants experienced being recruited and included in the study, as well as whether the necessary information was received and understood, helped to identify possible areas for improvement. In particular, this is exemplified by the participant who had not perceived participation in the study to involve the risk of liver metastases upon recurrence.

A disadvantage of this study is the small sample size that may limit the generalisability of the findings. However, qualitative research does not seek representativeness but rather to elucidate the phenomena that the participants experience from their own perspectives. Moreover, the sample selection proved to be adequate in this study, as the narratives were rich and full of nuanced examples.

In conclusion, we believe that the implementation of a qualitative approach in clinical trials can result in a better understanding of patients' perspectives and, therefore, lead to improved practice.

\section{Conflicts of Interest}

The Authors declare that they have no conflicts of interest to report.

\section{Authors' Contributions}

$\varnothing \mathrm{SB}$ came up with the initial concept for this study. Both $\varnothing \mathrm{SB}$ and LF developed the study design. ØSB and IH recruited the patients. LF and PHW conducted the interviews and then analysed and interpreted the qualitative data. LF, PHW, ØSB and IH participated in writing the manuscript. All the Authors have read and agreed to the published version of the manuscript.

\section{Acknowledgements}

The Authors wish to gratefully acknowledge all of the participants for their kind and invaluable contributions to the present study. They also wish to thank Jenny Engebretsen for her skilled transcription work. This study received financial support from Lilly Constance and Karl Ingolf Larssons Stiftelse (grant no. CRF/18004).

\section{References}

1 Nilsson B, Bümming P, Meis-Kindblom JM, Odén A, Dortok A, Gustavsson B, Sablinska K and Kindblom LG: Gastrointestinal stromal tumors: the incidence, prevalence, clinical course, and prognostication in the preimatinib mesylate era - a populationbased study in western Sweden. Cancer 103(4): 821-829, 2005. PMID: 15648083. DOI: 10.1002/cncr.20862

2 Joensuu H, Vehtari A, Riihimäki J, Nishida T, Steigen SE, Brabec P, Plank L, Nilsson B, Cirilli C, Braconi C, Bordoni A, Magnusson MK, Linke Z, Sufliarsky J, Federico M, Jonasson JG, Dei Tos AP and Rutkowski P: Risk of recurrence of gastrointestinal stromal tumour after surgery: an analysis of pooled population-based cohorts. Lancet Oncol 13(3): 265-274, 2012. PMID: 22153892. DOI: 10.1016/S1470-2045(11)70299-6

3 Hompland I, Bruland ØS, Hølmebakk T, Poulsen JP, Stoldt S, Hall KS and Boye K: Prediction of long-term survival in patients with metastatic gastrointestinal stromal tumor: analysis of a large, single-institution cohort. Acta Oncol 56(10): 1317-1323, 2017. PMID: 28557540. DOI: 10.1080/0284186X.2017.1330555

4 Demetri GD, von Mehren M, Blanke CD, Van den Abbeele AD, Eisenberg B, Roberts PJ, Heinrich MC, Tuveson DA, Singer S, Janicek M, Fletcher JA, Silverman SG, Silberman SL, Capdeville R, Kiese B, Peng B, Dimitrijevic S, Druker BJ, Corless C, Fletcher CD and Joensuu H: Efficacy and safety of imatinib mesylate in advanced gastrointestinal stromal tumors. N Engl J Med 347(7): 472-480, 2002. PMID: 12181401. DOI: 10.1056/NEJMoa020461

5 Demetri GD, van Oosterom AT, Garrett CR, Blackstein ME, Shah MH, Verweij J, McArthur G, Judson IR, Heinrich MC, Morgan JA, Desai J, Fletcher CD, George S, Bello CL, Huang $\mathrm{X}$, Baum CM and Casali PG: Efficacy and safety of sunitinib in patients with advanced gastrointestinal stromal tumour after failure of imatinib: a randomised controlled trial. Lancet 368(9544): 1329-1338, 2006. PMID: 17046465. DOI: 10.1016/S0140-6736(06)69446-4

6 Casali PG, Abecassis N, Aro HT, Bauer S, Biagini R, Bielack S, Bonvalot S, Boukovinas I, Bovee JVMG, Brodowicz T, Broto JM, Buonadonna A, De Álava E, Dei Tos AP, Del Muro XG, Dileo P, Eriksson M, Fedenko A, Ferraresi V, Ferrari A, Ferrari S, Frezza AM, Gasperoni S, Gelderblom H, Gil T, Grignani G, Gronchi A, Haas RL, Hassan B, Hohenberger P, Issels R, Joensuu H, Jones RL, Judson I, Jutte P, Kaal S, Kasper B, Kopeckova K, Krákorová DA, Le Cesne A, Lugowska I, Merimsky O, Montemurro M, Pantaleo MA, Piana R, Picci P, Piperno-Neumann S, Pousa AL, Reichardt P, Robinson MH, Rutkowski P, Safwat AA, Schöffski P, Sleijfer S, Stacchiotti S, Sundby Hall K, Unk M, Van Coevorden F, van der Graaf WTA, Whelan J, Wardelmann E, Zaikova O, Blay JY and ESMO Guidelines Committee and EURACAN: Soft tissue and visceral sarcomas: ESMO-EURACAN Clinical Practice Guidelines for diagnosis, treatment and follow-up. Ann Oncol 29(Suppl 4): iv51-iv67, 2018. PMID: 29846498. DOI: 10.1093/annonc/mdy096

7 Blay JY and Rutkowski P: Adherence to imatinib therapy in patients with gastrointestinal stromal tumors. Cancer Treat Rev 40(2): 242-247, 2014. PMID: 23931926. DOI: 10.1016/j.ctrv. 2013.07.005 
8 Sodergren SC, White A, Efficace F, Sprangers M, Fitzsimmons D, Bottomley A and Johnson CD: Systematic review of the side effects associated with tyrosine kinase inhibitors used in the treatment of gastrointestinal stromal tumours on behalf of the EORTC Quality of Life Group. Crit Rev Oncol Hematol 91(1): 35-46, 2014. PMID: 24495942. DOI: 10.1016/j.critrevonc.2014.01.002

9 Fauske L, Hompland I, Lorem G, Bondevik H and Bruland ØS: Perspectives on treatment side effects in patients with metastatic gastrointestinal stromal tumour: a qualitative study. Clin Sarcoma Res 9: 6, 2019. PMID: 31061697. DOI: 10.1186/s13569-0190116-3

10 Macdonald N, Shapiro A, Bender C, Paolantonio M and Coombs $\mathrm{J}$ : Experiences and perspectives on the GIST patient journey. Patient Prefer Adherence 6: 253-262, 2012. PMID: 22536061. DOI: $10.2147 /$ PPA.S24617

11 Poort H, van der Graaf WT, Tielen R, Vlenterie M, Custers JA, Prins JB, Verhagen CA, Gielissen MF and Knoop H: Prevalence, impact, and correlates of severe fatigue in patients with gastrointestinal stromal tumors. J Pain Symptom Manage 52(2): 265-271, 2016. PMID: 27233141. DOI: 10.1016/j.jpainsymman.2016.02.019

12 Mahon FX: Discontinuation of TKI therapy and 'functional' cure for CML. Best Pract Res Clin Haematol 29(3): 308-313, 2016. PMID: 27839571. DOI: 10.1016/j.beha.2016.10.014

13 Le Cesne A, Ray-Coquard I, Bui BN, Adenis A, Rios M, Bertucci F, Duffaud F, Chevreau C, Cupissol D, Cioffi A, Emile JF, Chabaud S, Pérol D, Blay JY and French Sarcoma Group: Discontinuation of imatinib in patients with advanced gastrointestinal stromal tumours after 3 years of treatment: an open-label multicentre randomised phase 3 trial. Lancet Oncol 11(10): 942-949, 2010. PMID: 20864406. DOI: 10.1016/S14702045(10)70222-9

14 Blay JY, Le Cesne A, Ray-Coquard I, Bui B, Duffaud F, Delbaldo C, Adenis A, Viens P, Rios M, Bompas E, Cupissol D, Guillemet C, Kerbrat P, Fayette J, Chabaud S, Berthaud P and Perol D: Prospective multicentric randomized phase III study of imatinib in patients with advanced gastrointestinal stromal tumors comparing interruption versus continuation of treatment beyond 1 year: the French Sarcoma Group. J Clin Oncol 25(9): 1107-1113, 2007. PMID: 17369574. DOI: 10.1200/JCO.2006.09.0183

15 Hompland I and Bruland ØS: Can Imatinib Be Safely Withdrawn in Patients with Surgically Resected Metastatic GIST? Anticancer Res 35(11): 5759-5765, 2015. PMID: 26503996

16 Kvale $S$ and Brinkmann S: Interviews: learning the craft of qualitative research interviewing. Los Angeles, CA, USA, Sage, 2009.

17 Edmonds WA and Kennedy TD: An applied guide to research designs: quantitative, qualitative, and mixed methods. 2nd edition, Los Angeles, CA, USA, Sage, 2017.

18 Gubrium JF, Holstein JA, Marvasti AB and McKinney KD: The SAGE handbook of interview research: the complexity of the craft. Thousand Oaks, CA, USA, Sage, 2012.

19 Braun V and Clarke V: Using thematic analysis in psychology. Qual Res Psychol 3: 24, 2006.

20 Braun V and Clarke V: Reflecting on reflexive thematic analysis. Qualitative Research in Sport, Exercise and Health 11(4): 589597, 2019. DOI: 10.1080/2159676X.2019.1628806
21 Nierop-van Baalen C, Grypdonck M, van Hecke A and Verhaeghe S: Hope dies last ... A qualitative study into the meaning of hope for people with cancer in the palliative phase. Eur J Cancer Care (Engl) 25(4): 570-579, 2016. PMID: 27098887. DOI: $10.1111 /$ ecc. 12500

22 Ebright PR and Lyon B: Understanding hope and factors that enhance hope in women with breast cancer. Oncol Nurs Forum 29(3): 561-568, 2002. PMID: 11979287. DOI: 10.1188/02.ONF. 561-568

23 Folkman S: Stress, coping, and hope. Psychooncology 19(9): 901-908, 2010. PMID: 20799373. DOI: 10.1002/pon.1836

24 Flynn KE, Myers JM, D'Souza A, Schiffer CA, Thompson JE and Atallah E: Exploring patient decision making regarding discontinuation of tyrosine kinase inhibitors for chronic myeloid leukemia. Oncologist 24(9): 1253-1258, 2019. PMID: 30944185. DOI: 10.1634/theoncologist.2018-0831

25 Verbrugghe M, Duprez V, Beeckman D, Grypdonck M, Quaghebeur M, Verschueren C, Verhaeghe S and Van Hecke A: Factors influencing adherence in cancer patients taking oral tyrosine kinase inhibitors: a qualitative study. Cancer Nurs 39(2): 153-162, 2016. PMID: 25815430. DOI: 10.1097/NCC.0000000000000250

26 Elwyn G, Frosch DL and Kobrin S: Implementing shared decisionmaking: consider all the consequences. Implement Sci 11: 114, 2016. PMID: 27502770. DOI: 10.1186/s13012-016-0480-9

27 Verheggen FW, Jonkers R and Kok G: Patients' perceptions on informed consent and the quality of information disclosure in clinical trials. Patient Educ Couns 29(2): 137-153, 1996. PMID: 9006231. DOI: 10.1016/0738-3991(96)00859-2

28 Penman DT, Holland JC, Bahna GF, Morrow G, Schmale AH, Derogatis LR, Carnrike CL Jr and Cherry R: Informed consent for investigational chemotherapy: patients' and physicians' perceptions. J Clin Oncol 2(7): 849-855, 1984. PMID: 6737023. DOI: 10.1200/JCO.1984.2.7.849

29 Cassileth BR, Zupkis RV, Sutton-Smith K and March V: Informed consent - why are its goals imperfectly realized? N Engl J Med 302(16): 896-900, 1980. PMID: 7360175. DOI: 10.1056/NEJM198004173021605

30 Muss HB, White DR, Michielutte R, Richards F 2nd, Cooper MR, Williams S, Stuart JJ and Spurr CL: Written informed consent in patients with breast cancer. Cancer 43(4): 1549-1556, 1979. PMID: 445353. DOI: 10.1002/1097-0142(197904)43: 4<1549::aid-cncr2820430449>3.0.co;2-r

31 Corn BW, Feldman DB and Wexler I: The science of hope. Lancet Oncol 21(9): e452-e459, 2020. PMID: 32888474. DOI: 10.1016/S1470-2045(20)30210-2

32 Pope C, Ziebland S and Mays N: Qualitative research in health care. Analysing qualitative data. BMJ 320(7227): 114-116, 2000. PMID: 10625273. DOI: 10.1136/bmj.320.7227.114

33 Gibson G, Timlin A, Curran S and Wattis J: The scope for qualitative methods in research and clinical trials in dementia. Age Ageing 33(4): 422-426, 2004. PMID: 15226116. DOI: 10.1093/ageing/afh136

Received November 25, 2021

Revised December 20, 2021

Accepted December 21, 2021 